\title{
Relações de poder em Roma: o patronato e a clientela
}

\author{
RENATA LOPES BIAZOTTO VENTURINI \\ Departamento de História \\ Universidade Estadual de Maringá
}

\begin{abstract}
RESUMO: Neste artigo, são focalizadas as relações de poder em Roma, estudando-se particularmente o pensamento político fundamentado no patronato e na clientela durante o Principado.
\end{abstract}

PALAVRAS-CHAVE: poder; patronato; clientela; vocabulário político.

\section{Introdução}

As relações de poder apresentam formas particulares e variáveis e suas variações exercem influência sobre o sentido dos termos que são utilizados para traduzir o exercício do poder no interior da vida política. No caso romano, identifica-se a inexistência de uma política teórica diante de uma concepção puramente pragmática da vida política.

Nesse sentido, não seriam encontradas em Roma as condições necessárias para a constituição verdadeira de partidos políticos na moderna acepção do termo, isto é, de agentes políticos por excelência da sociedade moderna, com interesses determinados, em relação aos quais, têm compromissos que lhes conferem significado.

As diferenças consideráveis entre as sociedades antigas e as modernas já foram identificadas por J. Hellegouarc'h (1963), ao promover um estudo da vida política dos romanos através do vocabulário. A razão desta diferença reside, segundo o historiador, no exame das estruturas particulares do Estado romano e no modo de vida de seus concidadãos, onde se esconde, sob o nome de partido, uma realidade complexa que está ligada a elementos de ordem constitucional e a elementos de ordem social.

No que concerne aos elementos de ordem constitucional, J. Hellegouarc"h (Hellegouarc'h, 1963, p. 159) destaca três fatores, a saber: o sistema eleitoral, a gratuidade e a anuidade das magistraturas. Os magistrados, restritos a um pequeno círculo de famílias abastadas, acabaram por controlar e por limitar o poder das assembléias. Além disso, as magistraturas anuais não possibilitavam o estabelecimento de um programa político:

.... Roma vivia num perpétuo clima de campanha eleitoral, favorável a todos os excessos da demagogia.

Ao caracterizar os elementos de ordem social, Hellegouarc'h (Hellegouarc'h, 1963, p. 158) afirma que toda a organização da sociedade romana refletia a influência determinante 
e eficaz que certos indivíduos exerciam sobre o conjunto dos outros. Existiam em Roma, agrupamentos que uniam um certo número de indivíduos com interesses políticos comuns, o que cristalizava a existência de grupos políticos:

Há de um lado, a elite daqueles que governam, e de outro lado, a massa daqueles que obedecem. (...) Essa divisão da sociedade se exprime tradicionalmente na oposição patres-plebs, mas ela se manifesta sobretudo na instituição do patronato e da clientela.

É neste quadro que se propõe um estudo das relações de poder em Roma, isto é, um estudo do pensamento político dos romanos - fundamentados no patronato e na clientela durante o período identificado pela historiografia como Principado.

Tal estudo inicia-se com algumas considerações sobre o patronato romano, identificando-o como uma relação de caráter pessoal que se estabelece entre membros de categorias sociais divergentes. A partir desta divergência, são destacados os laços que unem o patrono ao cliente, através do exame de termos como fides e amicitia, determinadores das qualidades pessoais que lhes são indispensáveis para o estabelecimento da auctoritas política.

\section{O patronato: considerações preliminares}

O patronato se apresenta como um sistema marcado pela ambigüidade e pela flexibilidade. Ambigüidade na relação patrono-cliente, e flexibilidade no acesso para o conhecimento e posterior integração no interior da sociedade romana.

Três fatores são característicos do patronato, segundo o historiador inglês Richard Saller (Saller, 1989, p. 49): a relação patronal envolve uma troca recíproca de bens e serviços, deve ser uma relação pessoal e deve ser uma relação assimétrica, ou seja, patrono e cliente são membros de categorias sociais distintas.

Partindo desta caracterização, Saller (Saller, 1989, p. 58) questiona-se a respeito dos laços que se estabelecem no interior da relação patronal. Neste caso específico, os próprios vocábulos empregados pelo romano, como cliens, amicus, patronus, revelam a existência de diferentes formas de comportamento no interior de tal relação. Todavia, mais importante que este vocabulário é o conjunto das obrigações que se estabelecem entre o patrono e o cliente. $\mathrm{O}$ autor lembra a importância da visita matinal - salutatio - ao patrono, afirmando que:

As ambições buscadas pelos novos homens aspirando construir seus caminhos na aristocracia imperial, foram associadas à necessidade de cultivar o favor dos grandes para prestar as salutationes.

Muito embora o estudo de Richard Saller identifique a existência de laços recíprocos baseados na lealdade entre as partes envolvidas, desconsidera uma ambigüidade inerente a relação patronal. Tais laços nem sempre foram respeitados. Certamente, pode-se demonstrar a relevância da prática das salutationes, como faz o próprio autor ao considerar os Epigramas do poeta Marco Valério Marcial'. Entretanto, o mesmo poeta sugere comportamentos diversos entre patrono e cliente.

Muitos são os exemplos presentes nos escritos de Marcial que estão diretamente ligados ao comportamento ambíguo no interior da relação patronal. O poeta destaca a 
bajulação, o exibicionismo, a desonestidade. O Epigrama XII constitui-se num exemplo tácito da arte de adular:

Tu tens dez doenças por ano, ou ainda mais, e não és tu quem sofre com isso, Policarmo, mas nós: pois quando deixas o leito em que estiveste durante a tua convalescença pedes presentes aos amigos. Tem um pouco de pudor, Policarmo; não finjas estar doente (Marc. Ep. XII, 56, 1-3).

A relação entre os Epigramas e a realidade social a partir da relação patronal, mostra-se, portanto, mais complexa. Marcial dá conselhos grátis, mas não esquece a sua condição de cliente. A única escolha fora de seu alcance, caso desejasse prosseguir na sua profissão de poeta era a dos patroni:

Meu pequeno livro, em que direção tu queres ir como presente? Apressa-te para encontrar um protetor (...). Tu te refugias no seio de Faustino? Excelente idéia! (III, 2, 1-4).

Marcial é, na verdade, um cronista do cotidiano. Ele trabalha temas que interessam aos amici ricos, não sem antes dar-lhes uma tonalidade jocosa. Esta linguagem é muito bem aceita socialmente, até porque a sociedade romana também apreciava os seus porta-vozes. Esta apreciação releva, em parte, o conhecimento da intimidade e da personalidade das pessoas retratadas, o que as tornava acessíveis ao público e, por conseguinte, conhecidas.

Ainda no interior desta discussão, merece menção o estudo de Andrew Wallace-Hadrill (Wallace-Hadrill, 1989, p. 74). O historiador sugere discussões análogas àquelas de Saller. Ele entende o patronato como uma relação pessoal entre desiguais, também baseada na existência de uma troca recíproca. Todavia, acrescenta em sua argumentação, que o patronato não é somente uma estrutura de poder, mas também um sistema para a reprodução do poder:

O sistema político romano em todos os tempos, demonstrou algum tipo de direito regional na representação no governo. Entretanto, o acesso era mediado através de indivíduos. Foi essa inacessibilidade ao centro, exceto através de círculos pessoais, que gerou o poder do patronato, e foi através do exercício deste poder que o patronato colocou a integração social sem limites e assegurou o controle social.

Desta forma, um sistema de patronato entre indivíduos e baseado na troca recíproca, implica igualmente no estabelecimento de alianças de patronos poderosos para obter recursos, inclusive aquele ligado a lealdade do cliente.

Wallace-Hadril acrescenta em sua proposta de análise que o patronato, na sociedade romana, também envolveu laços entre indivíduos de níveis sociais diversos. A relação patronal envolve troca entre aqueles que estão mais próximos do centro do poder e entre aqueles que estão mais distantes dele, tendo como objetivo mediar recursos através das relações pessoais. É possível concluir, segundo o autor, que já no final do período republicano romano, o sistema do patronato era a forma pela qual as atividades do Estado foram mobilizadas, sofrendo ampliações com a expansão imperial. O efeito mais significativo deste processo se fazia presente na figura do imperador, que em virtude de sua posição, podia controlar o acesso aos recursos do sistema. 
Nesse sentido, Wallace-Hadrill identifica o exercício de um patronato universal, pois, sob o Império, ocorreu uma variedade de adaptações com a inclusão dos novi homines na comunidade política de Roma, o que gerou uma ampliação das alianças estabelecidas na relação pessoal entre patrono e cliente.

Nestas breves considerações tecidas sobre o patronato romano, da perspectiva de Richard Saller e Andrew Wallace-Hadrill, deve-se destacar que o sistema patronal mostrase como um veículo reprodutor da estrutura de poder onde é essencial a capacidade e a habilidade que o patrono demonstra para a aquisição de clientes.

\section{Patrono/ cliente: relações fundadas sobre a fides e a amicitia}

$\mathrm{Na}$ origem das relações políticas fundadas sobre as relações pessoais entre patrono e cliente, é natural encontrar a noção de fides e amicitia. Um homem político deve apoiar-se sobre um conjunto de relações nas quais os amici representam o elemento mais importante. Deve-se reconhecer que não se trata de uma particularidade própria de Roma; na atualidade, um deputado também fala de seus "amigos políticos", que são membros de seu partido. No caso romano observa-se a existência de grupos com interesses políticos comuns. J. Hellegouarc'h, (Hellegouarc'h,1963, p. 161) já anteriormente mencionado, destaca que:

O que faz o caráter original e profundamente romano destes grupos políticos é que, qualquer que seja a tarefa a que se proponham e o sentimento que os anime, estão fundados sobre uma noção específica, que domina verdadeiramente todo o vocabulário político dos romanos: a fides.

O conceito de fides corresponde a uma idéia de confiança mútua e indica os laços recíprocos existentes entre aqueles que estão unidos por uma mesma amicitia. A fides relaciona-se ao cliente - ou amicus - e apresenta um duplo sentido. Ou seja, aplicando-se àqueles que são protegidos - cliens - designa a confiança colocada naquele que o protege patronus; aplicando-se ao protetor - patronus - exprime a confiança que ele inspira. Assim, o caráter próprio da fides demonstra, concomitantemente, a existência de um dever entre patrono-cliente, denominado officium.

O officium designa as obrigações recíprocas que se impõem àqueles que estão unidos por uma mesma amicitia. Esta relação tem por base um tipo de contrato fazendo com que a proteção concedida pelo patrono, deva ser paga pelo apoio que o cliente lhe presta em circunstâncias que se fazem necessárias e úteis. Nestas condições, o cliente torna-se devedor para com o patrono.

Os deveres impostos pelo officium assumem diversas formas na vida política e social. Podem ser obrigações puramente sociais, tais como commendatio, suffragatio, salutatio, deductio; mas também, sob uma forma mais precisamente política, significam o sustento e o apoio que são dirigidos ao patrono.

Por outro lado, um número elevado de termos vem caracterizar as qualidades dos patronos, como fortitudo, labor, diligentia, industria. Há ainda outros termos revestidos de um caráter filosófico que se traduzem no comportamento virtuoso de um lider político: prudentia, sapientia, iustitia, clementia, temperantia, humanitas. Este conjunto de termos 
destacado por J. Hellegouarc'h (Hellegouarc'h, 1963, p.162), comporta as qualidades de um patrono, conferindo-lhe também sua autoridade e influência - auctoritas.

A noção de auctoritas indica os meios de que o patrono dispõe em dinheiro, amizades e clientes para assegurar seu poder social e político, implicando superioridade e prioridade. Superioridade sobre os demais membros da comunidade, e prioridade para tomar iniciativas e enunciá-las ao Senado Romano.

A amicitia se mostra, portanto, como um instrumento de ação política, e, neste caso, o caráter mais ou menos desinteressado destas amizades não é uma especialidade romana. Todavia, o que caracteriza Roma é que o homem político, na ausência de partidos organizados, utiliza-se deste recurso para estender sua influência e se ligar a um maior número de pessoas. A amicitia não repousa sobre relações construídas ao acaso; trata-se de uma verdadeira organização que impõe a seus membros obrigações variadas.

Pode-se observar que o conceito de fides e o conceito de amicitia, bem como todas as relações deles decorrentes, estão inseridos num espaço político de onde se vê desdobrar a condição social, ou, mais propriamente, a posição que cada um ocupa na escala social, o lugar que lhe é devido.

\section{O cliente}

Ao considerar-se o cliente, deve-se observar a dificuldade de defini-lo no interior da sociedade romana. Nesse sentido afirma R. Marache (Marache, 1961, p. 12-13):

A palavra cliente não evoca uma categoria social definida. O laço que une o cliente ao seu patrono é uma espécie de laço dedependência. Um homem rico e poderoso pode ser o cliente de um outro, ainda mais rico ou mais nobre. Muitos artesãos ou pessoas que exercem pequenos negócios, encontram-se colocados na clientela de uma grande família. (...) Nada era mais honroso do que fazer parte da clientela de uma grande família.

Robert Marache identifica o clientelismo como um problema de caráter social, o que vem a ser precisamente o centro da poesia de Marcial e Juvenal, intérpretes de um mal profundo, o mal-estar de toda uma classe social.

Este mal-estar social, identificado pelo autor, impõe diversas formas de comportamento, ora elogiadas, ora repudiadas por Marcial e Juvenal ${ }^{2}$. O que se destaca é a imagem deformada do patrono, não assumindo o mesmo papel do protetor de outrora. O laço da clientela deixou de ser uma relação humana e pessoal. A própria instituição se degradou, e não se considera mais o cidadão pobre como homem; ricos e pobres não se encontram mais; são essências diferentes (Marache, 1961, p.15-16). No Epigrama XII, 13, Marcial o demonstra claramente: "Ó Auto, para os ricos a ira é uma forma de lucro. Odiar custa menos que dar".

Se a relação patronal é estabelecida entre desiguais, se para o patrono a posse de clientes é sinônimo de notoriedade e riqueza, há que se considerar que há elementos que permitem identificar o contraste entre patrono-cliente. É possível estabelecer-se uma relação entre clientela e pobreza?

Para Charles R. Whittaker (Whittaker, 1992, p. 231), sim. O autor apresenta dois elemntos fundamentais ao empreender a tarefa de definir condições como riqueza e pobreza entre os romanos. A princípio destaca o problema da distribuição da riqueza. Sob este as- 
pecto, as estruturas jurídicas da sociedade e suas estruturas reais não são equivalentes, isto é, nem sempre a estrutura jurídica do indivíduo corresponde a sua real condição de sobrevivência. Destaca como exemplos escravos, ex-escravos, aos quais foi concedida a liberdade, e estrangeiros. Em todos os casos, existem pobres e ricos. Há, portanto, uma 'pobreza relativa' ou 'vários níveis de pobreza'.

O segundo elemento apresentado por Whittaker diz respeito à condição de vida na Urbs. Roma, capital do Império, cresce e torna-se um polo de atração. Já no final do século I a.C., amplia-se o afluxo para Roma de homens, mulheres e crianças de diferentes regiões do mundo romano, o que sugere um crescimento de diferentes problemas no plano da infraestrutura urbana, principalmente no tocante à manutenção desta população.

Roma apresenta-se como centro aglutinador de uma população diferenciada que encontrava na Urbs o espaço para o exercício de atividades artesanais e comerciais pouco rendosas.

É neste quadro que se insere o cliente para C. Whittaker. O laço de dependência que se estabelecia no interior do patronato permitia que um patrono dominasse o seu cliente mais pobre. Logo pela manhã o cliente fazia uma visita matinal ao seu patrono, a salutatio. Esta visita chegava a ser um rito que confirmava o laço da clientela. Ao vir cortejá-lo o cliente aspirava a sua proteção, aspirava fazer carreira pública; ou até mesmo ser incluído em seu testamento, quando pertencesse a mesma categoria social que seu patrono.

Assim sendo, existia entre os clientes uma ordem hierárquica, o que delimitava formas diferenciadas de tratamento. O patrono, ao receber em sua casa as saudações individuais de um certo número de clientes, estava recebendo um fragmento da sociedade romana, com seus diferentes níveis e desigualdades públicas, sobre a qual ele tinha a auctoritas.

\section{O patrono: a auctoritas política}

Pode-se entender a política na Antigüidade Romana enquanto formas de condução do governo, as decisões políticas e sua ideologia. Assim já a entendeu o historiador Moses Finley (Finley, 1980, p. 49). Particularmente com relação ao patronato, ele afirma que:

Na Antigüidade, a benevolência raramente era desinteressada, seja em relação a iguais ou a inferiores. Um objetivo era o estabelecimento da relação patrono-cliente e de conjunto de ligações, e, em decorrência disso, o reforço da aprovação da estrutura de poder e autoridade predominante na sociedade.

De um modo geral, Roma revelava uma contínua aceitação de suas instituições políticas, de forma tal a manter a estabilidade do Estado (Finley, 1980, p.37) Tal procedimento se justificava pelo apego ao passado mítico e glorioso que vinha legitimar o poderio romano, no qual a virtude dos ancestrais deveria orientar os passos da nova geração. Com isto, buscava-se, no plano do discurso e no plano religioso, resgatar os antigos valores mos maiorum - que orientariam a classe política.

Uma segunda justificativa que vem reforçar a aceitação da elite e suas pretensões de domínio era a tradição oral. Finley (Finley, 1980, p. 43) destaca que o 'mundo antigo 
permaneceu, predominantemente, um mundo da palavra falada, não da palavra escrita'. Nesse sentido, o acesso à informação e às leis, dependia essencialmente da comunicação oral; uma porta entreaberta para a elite para a divulgação de seus interesses.

Uma terceira e última justificativa refere-se à relação entre os líderes políticos e os cidadãos. Moses Finley (Finley, 1980, p. 56) chama a atenção para a necessidade de se considerar a auctoritas política. Ela se substanciava no estabelecimento de uma política tributária, um tipo de patronato comunitário e na relação patrono/cliente.

A auctoritas constituia-se na expressão do poder e da influência política em Roma. A importância política do patrono era determinada por um certo número de fatores materiais, intelectuais e morais, cujo conjunto determinava sua capacidade de exercer uma função dirigente e sua superioridade sobre seu círculo de relações.

Portanto, a auctoritas exprimia a superioridade do patrono, fundada tanto na sua situação social quanto nas suas qualidades pessoais - virtus. Ela tinha a capacidade de legitimar a confiança mútua - fides - que se estabelecia entre o patrono e o cliente. Mas este poder não estava ligado a uma função; sua natureza era resultante do sentimento recíproco no interior da relação patronal.

É neste quadro que a capacidade de convencimento e persuasão explicavam a importância da eloqüência, tanto no domínio jurídico quando no domínio político. Apoiada no mos maiorum, a auctoritas indicava a capacidade daquele que a possuia de receber o reconhecimento em seu círculo de relações pessoais.

Assim se apresentava a auctoritas de um homem político. Ela representava um poder de caráter pessoal e privado. A auctoritas comportava, portanto, uma mistura de poder político e de prestígio social.

\section{Considerações finais}

O tema deste artigo partiu de uma interrogação sobre as relações de poder na Antigüidade Romana. Ao se considerar as diferentes vertentes de leitura do tema, buscou-se apresentar um estudo do pensamento político dos romanos, fundado no patronato e na clientela sob o Principado, ressaltando-se o aspecto social que envolve a concepção de homem político no exercício de suas funções dirigentes.

Para se entender as dimensões do patronato e da clientela na sociedade romana, é mister pensar em relações que se estabeleciam entre aqueles que almejavam objetivos diferenciados, assim como sobre os diversos laços que envolviam indivíduos de diferentes níveis sociais. O uso de termos como patronus, cliens, amicus, fides, amicitia, auctoritas, foi aplicado em um extenso campo de vínculos entre homens de status distintos.

Na relação do homem político com seus concidadãos, não havia o instrumento de um partido e de todo seu aparelho administrativo. O sucesso de um candidato era consequiência de um conjunto de relações complexas, mas que eram sempre relações pessoais.

Nesse sentido, destacou-se a importância da fides, uma vez que esta noção definia os laços que uniam o patrono ao cliente e o conjunto de obrigações recíprocas. Sua relevância para o homem político ou patrono, mostrava-se no conjunto de elementos materiais, intelectuais e morais que ele tinha a capacidade de reunir, e que possibilitavam o reconhecimento de sua auctoritas. Enquanto para o patrono receber o apoio do cliente era sinônimo de notoriedade e riqueza, para o cliente a relação patronal marcava sua condição no interior da sociedade romana, bem como a ambigüidade no respeito à fides. 
Tal ambigüidade se faz presente nos poemas de Marcial. Como cliente que era, as virtudes morais mais discretas estavam ausentes de sua ética. Os condimentos mais importantes que figuram em seus Epigramas são a ousadia, a voluntariedade e o êxito, e por detrás deles, aparece a riqueza, sem a qual a amicitia estabelecida como referência no patronato, não seria possível.

\section{Notas}

1 - Marco Valério Marcial [Marcus Valerius Martialis (44-102 d.C.)], foi autor de Epigramas, em doze livros. Viveu em Roma na condição de poeta e cliente, onde em vão buscou adquirir fortuna como escritor. Os epigramas, oferecidos como presentes a amigos ou apresentados em locais públicos, são poemas concisos e indicadores de idéias simples, dirigidos a um destinatário individual ou imaginário. Os assuntos tratados revelam formas de comportamento na Urbs, onde se encontram beberrões, gulosos, avarentos, esposas devotadas ou libertinas, homossexuais, exibicionistas, delatores.

2 - Juvenal [Decimus Junius Juvenalis (60 ou 70 d.C. - ?)] foi um grande satirista romano. Suas sátiras são em número de dezesseis. Através delas, ele ataca os vícios, os abusos e as loucuras da vida em Roma.

\section{Referências bibliográficas}

FINLEY, Moses I. A política no mundo antigo. Tradução de Álvaro Cabral. Rio de Janeiro: Zahar, 1980.

HELLEGOUARC'H, J. La vie politiques des romaines à travers le vocabulaire. L'Information Littéraire. Paris, J. B. Baillière et Fils, 4, p. 158-166, set./oct. 1963.

MARACHE, R. Le poésie romaine et le problème social à la fin du Ier. Siècle: Martial et Juvenal. L'Information Littéraire. Paris, J. B. Baillière et Fils, 1, p. 12-19, jan./fev. 1961.

MARTIALIS, Marcus. Valerius Epigrammes. Traduit par H. J. Izaac. Paris: Les Belles Lettres, 1961.

SALLER, Richard. Patronage and friendship in early imperial Rome: drawing the distinction. In: WALLACE-HADRILL, A. (Ed.) Patronage in ancient society. London and New York: Routledge, 1989. p. 49-62.

WALLACE-HADRILL, A. Patronage in roman society: from Republic to Empire. In: (Ed.). Patronage in ancient society. London and New York: Routledge, 1989. p.63-88.

WHITTAKER, Charles R. O pobre. In: GIARDINA, Andrea (Dir.) O homem romano. Traduzido por Maria Jorge V. de Figueiredo. Lisboa: Editorial Presença, 1992. p. 225-248. 
VENTURINI, Renata L.B. Relations of power in Rome: the patronage and the clientelage. Classica, São Paulo, 11/12, p. 297-305, 1998/1999.

ABSTRACT: This article focuses the relations of power in Rome and, in particular, the study of the political thought based in the patronage and clientelage, in Principate.

KEY-WORDS: power; patronage; clientelage; political vocabulary. 